\title{
Performance and microbial community composition in a long-term sequential anaerobic-aerobic bioreactor operation treating coking wastewater
}

\author{
Dev Raj Joshi ${ }^{1,2} \cdot$ Yu Zhang ${ }^{1,3} \cdot$ Zhe Tian $^{1} \cdot$ Yingxin Gao ${ }^{3} \cdot$ Min Yang $^{3,4}$
}

Received: 31 January 2016/Revised: 25 April 2016/Accepted: 28 April 2016/Published online: 25 May 2016

(C) Springer-Verlag Berlin Heidelberg 2016

\begin{abstract}
The combined anaerobic-aerobic biosystem is assumed to consume less energy for the treatment of high strength industrial wastewater. In this study, pollutant removal performance and microbial diversity were assessed in a longterm (over 300 days) bench-scale sequential anaerobicaerobic bioreactor treating coking wastewater. Anaerobic treatment removed one third of the chemical oxygen demand (COD) and more than half of the phenols with hydraulic retention time (HRT) of $42 \mathrm{~h}$, while the combined system with total HRT of $114 \mathrm{~h}$ removed 81.8, 85.6, 99.9, 98.2, and 85.4\% of COD, total organic carbon (TOC), total phenols, thiocyanate, and cyanide, respectively. Two-dimensional gas chromatography with time-of-flight mass spectrometry showed complete removal of phenol derivatives and nitrogenous heterocyclic compounds (NHCs) via the combined system, with the
\end{abstract}

Electronic supplementary material The online version of this article (doi:10.1007/s00253-016-7591-8) contains supplementary material, which is available to authorized users.

Yu Zhang

zhangyu@rcees.ac.cn

Yingxin Gao

gyx@rcees.ac.cn

1 Key Laboratory of Drinking Water Science and Technology, Research Center for Eco-Environmental Sciences, Chinese Academy of Sciences, Beijing 100085, China

2 University of Chinese Academy of Sciences, Beijing 100049, China

3 Beijing Key Laboratory of Industrial Wastewater Treatment and Resource Recovery, Research Center for Eco-Environmental Sciences, Chinese Academy of Sciences, Beijing 100085, China

4 State Key Laboratory of Environmental Aquatic Chemistry, Research Center for Eco-Environmental Sciences, Chinese Academy of Sciences, Beijing 100085, China anaerobic process alone contributing 58.4 and $58.6 \%$ removal on average, respectively. Microbial activity in the bioreactors was examined by 454 pyrosequencing of the bacterial, archaeal, and fungal communities. Proteobacteria (61.2-93.4\%), particularly Betaproteobacteria (34.4-70.1\%), was the dominant bacterial group. Ottowia (14.1-46.7\%), Soehngenia (3.0-8.2 \%), and Corynebacterium (0.9-12.0\%), which are comprised of phenol-degrading and hydrolytic bacteria, were the most abundant genera in the anaerobic sludge, whereas Thiobacillus (6.6-43.6 \%), Diaphorobacter (5.1-13.0\%), and Comamonas $(0.2-11.1 \%)$ were the major degraders of phenol, thiocyanate, and NHCs in the aerobic sludge. Despite the low density of fungi, phenol degrading oleaginous yeast Trichosporon was abundant in the aerobic sludge. This study demonstrated the feasibility and optimization of less energy intensive treatment and the potential association between abundant bacterial groups and biodegradation of key pollutants in coking wastewater.

Keywords Coking wastewater $\cdot$ Anaerobic-aerobic process · Microbial communities $\cdot$ Biodegradation

\section{Introduction}

Coking wastewater (CWW) generated during coke production has garnered wide attention due to its mixture of diverse organic contaminants that are hazardous to ecosystems and human health (Song et al. 2013; Zhang et al. 2013; Felföldi et al. 2010; Zhao et al. 2014; Hou et al. 2015). CWW is generally treated by biological methods such as conventional activated sludge processes (Vazquez et al. 2006; Maranon et al. 2008). Despite the toxicity of contaminants like cyanides $\left(\mathrm{CN}^{-}\right)$and phenols (Kim et al. 2008; Sharma et al. 2012), aerobic activated sludge processes can effectively remove phenol 
derivatives, polyaromatic hydrocarbons (PAH), nitrogenous heterocyclic compounds (NHCs), thiocyanate $\left(\mathrm{SCN}^{-}\right)$, thiosulfate (Felföldi et al. 2010; Vazquez et al. 2006; Zhang et al. 2013; Bai et al. 2009; Sharma and Philip 2015; Shoji et al. 2014), releasing sulfate $\left(\mathrm{SO}_{4}{ }^{2}\right)$, and ammonia $\left(\mathrm{NH}_{4}{ }^{+}\right)$ into treated effluent (Staib and Lant 2007). However, aerobic processes require high energy input, generate large volumes of sludge, and do not adapt well to influent fluctuations (Wang et al. 2011). Toxic components of CWW are generally reduced by applying pretreatment methods like ammonia stripping and solvent extraction (Chen et al. 2012; Yuan et al. 2012), but the concentration of refractory compounds in pretreated effluent remains high (Wang et al. 2010).

Due to its reduced energy consumption, enhanced hydrolysis of organics, and detoxification of toxic compounds (Chakraborty and Veeramani 2002), anaerobic digestion is often used before an aerobic reactor for the treatment of high strength industrial wastewater (Wei et al. 2012), including the treatment of CWW or coal gasification wastewater (Wang et al. 2011; Zhu et al. 2013, 2016). However, although the efficiency of pollutant removal (such as of phenols) is low in many cases (Zhu et al. 2016), methane production appears to be limited under mesophilic conditions (Wang et al. 2011). Of note, free $\mathrm{CN}^{-}$in synthetic CWW has been reported to inhibit gas production (Sharma and Philip 2015). Therefore, the removal of pollutants in CWW by anaerobic treatment should be further studied.

The biodegradation of a pollutant corresponds to the functional activity of microbial communities established in wastewater treatment systems (Wagner and Loy 2002; Wells et al. 2011). Since these microbial populations are associated with pollutant removal efficiency, understanding community structure in different stages during long-term operated CWW treatment is important. Previous studies have focused on bacterial diversity surveys in full-scale CWW treatment systems, revealing the distribution of potential degraders of phenols, $\mathrm{SCN}^{-}$, and $\mathrm{CN}^{-}$(Zhu et al. 2013, 2016; Ma et al. 2015a; Wang et al. 2015b). However, to better understand the profiles of acclimatized bacterial, archaeal, and fungal communities associated with degradation of different pollutants, research on controlled sequential anaerobic and aerobic CWW treatment systems is desirable.

In this study, the performance of a bench-scale sequential anaerobic and aerobic system was monitored for over 300 days. The removal of major contaminants, including phenol derivatives and NHCs, was evaluated for each step using comprehensive two-dimensional (2D) gas chromatography with time-of-flight mass-spectrometry $(\mathrm{GC} \times \mathrm{GC}$-TOF-MS) together with $\mathrm{SCN}^{-}$and $\mathrm{CN}^{-}$under stable operation. Concomitantly, microbial community compositions and abundances in sludge samples were analyzed by applying Roche 454 pyrosequencing and real-time quantitative polymerase chain reaction (qPCR). This study highlights the feasibility and optimization of less energy intensive treatment and provides insight on the diverse microbial groups with potential to degrade major pollutants of CWW.

\section{Materials and methods}

\section{Bench-scale wastewater treatment system}

A bench-scale system consisting of an up-flow anaerobic sludge blanket reactor (UASB) and a conventional aerobic bioreactor was used for the treatment of real CWW (Fig. 1). The hydraulic retention times (HRT) were 42 and $72 \mathrm{~h}$ for the UASB ( $2 \mathrm{~L})$ and aerobic reactors $(3.5 \mathrm{~L})$, respectively. The system was operated at an ambient temperature of $20-25^{\circ} \mathrm{C}$, and dissolved oxygen (DO) was maintained at $2-4 \mathrm{mg} / \mathrm{L}$ in the aerobic reactor for the whole period (over 300 days). The concentration of suspended solids in the aerobic reactor was maintained at $3000-4000 \mathrm{mg} / \mathrm{L}$. The seed sludge was obtained from a full-scale sewage treatment plant in Beijing, China.

Raw CWW was taken from the equalization tank of a coking facility in Tangshan City, Hebei Province, China. After the recovery of ammonia and phenol, the CWW had a chemical oxygen demand (COD) of $2500-3500 \mathrm{mg} / \mathrm{L}$ (Table $\mathrm{S} 1$ in ESM). Prior to treatment, the raw wastewater was supplemented with $0.2 \mathrm{~g} / \mathrm{L}$ of potassium phosphate mono-basic $\left(\mathrm{KH}_{2} \mathrm{PO}_{4}\right)$ and $1 \mathrm{ml} / \mathrm{L}$ of micronutrient solution $(2000 \mathrm{mg}$ $\mathrm{FeCl}_{2} \cdot 4 \mathrm{H}_{2} \mathrm{O}, 2000 \mathrm{mg} \mathrm{CoCl} \cdot 6 \mathrm{H}_{2} \mathrm{O}, 500 \mathrm{mg} \mathrm{MnCl} \cdot 4 \mathrm{H}_{2} \mathrm{O}$, $30 \mathrm{mg} \mathrm{CuCl} 2 \cdot 2 \mathrm{H}_{2} \mathrm{O}, 50 \mathrm{mg} \mathrm{ZnCl}_{2}, 50 \mathrm{mg} \mathrm{H}_{3} \mathrm{BO}_{3}, 90 \mathrm{mg}$ $\mathrm{AlCl}_{3} \cdot 6 \mathrm{H}_{2} \mathrm{O}, 90 \mathrm{mg}\left(\mathrm{NH}_{4}\right)_{6} \mathrm{Mo}_{7} \mathrm{O}_{24} \cdot 4 \mathrm{H}_{2} \mathrm{O}, 100 \mathrm{mg}$ $\mathrm{Na}_{2} \mathrm{SeO}_{3} \cdot 5 \mathrm{H}_{2} \mathrm{O}, 50 \mathrm{mg} \mathrm{NiCl} \cdot 6 \mathrm{H}_{2} \mathrm{O}, 1000 \mathrm{mg}$ EDTA, $1 \mathrm{ml}$ $36 \% \mathrm{HCl}$, and $500 \mathrm{mg}$ resazurin in $1 \mathrm{~L}$ of deionized distilled water). The $\mathrm{pH}$ of the influent wastewater was adjusted to $7.5 \pm 0.5$ using concentrated hydrochloric acid solution.

\section{Samples and sampling}

The grab wastewater samples of influent and effluent from different sampling points (Fig. 1) were collected every 57 days and analyzed to monitor bioreactor performance. For the determination of organic and inorganic compounds, wastewater samples were collected in triplicate before the termination of bioreactor operation. For microbiological analysis, anaerobic and aerobic sludge samples were collected in parallel on days $125,194,228,276$, and 325 , with aerobic sludge samples also collected on days 174 and 261 . Spatially composite sludge samples were prepared by mixing together sub-samples collected from at least three sampling points of the reactor. The samples were then re-distributed as $1 \mathrm{~mL}$ of anaerobic sludge and $1.5 \mathrm{~mL}$ of aerobic sludge into 2-mL centrifuge tubes separately, and were then centrifuged at $10,000 \mathrm{rpm}$ for $10 \mathrm{~min}$ at $4{ }^{\circ} \mathrm{C}$, and stored at $-20^{\circ} \mathrm{C}$ until DNA extraction. 
Fig. 1 A schematic diagram showing bench-scale anaerobicaerobic system treating coking wastewater in this study. Wastewater sample collection points include influent $(W 1)$, anaerobic effluent $(W 2)$, and aerobic effluent $(W 3)$

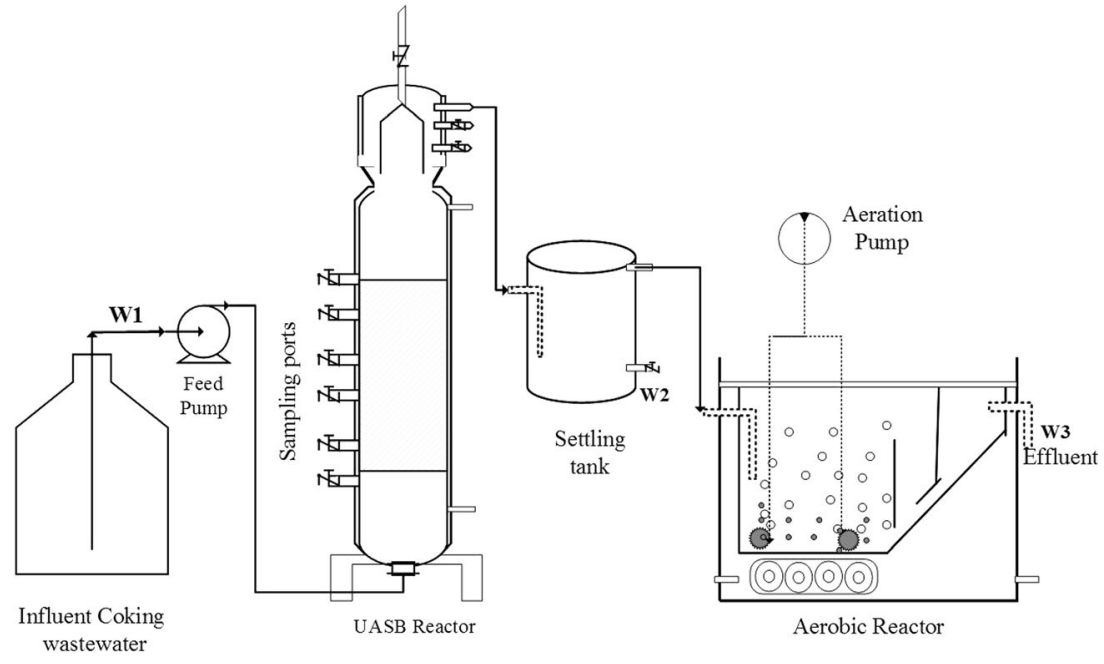

\section{Methods for routine analyses}

Prior to chemical analyses, the water samples were centrifuged at $9000 \mathrm{rpm}$ for $10 \mathrm{~min}$ and then filtered through a $0.45-\mu \mathrm{m}$ membrane filter. The COD was determined by the open reflux method (APHA 2005). Total phenol (4-amino antipyrine reagent), total nitrogen (persulfate method), ammonia-nitrogen (nesslerization), thiocyanate $\left(\mathrm{SCN}^{-}\right)$(as ferric thiocyanate), and free $\mathrm{CN}^{-}$(chloramine T reagent) were measured by spectrophotometry (Shimadzu UV-160, Japan) (APHA 2005). The TOC was determined using a TOC analyzer (Teledyne Tekmar, USA), and sulfate $\left(\mathrm{SO}_{4}{ }^{2-}\right)$ was analyzed by ion chromatography (ICS-1000; Thermo Scientific, USA) eluted isocratically with $1.0 \mathrm{mM} \mathrm{NaHCO} / 3.5 \mathrm{mM}$ $\mathrm{Na}_{2} \mathrm{CO}_{3}$ at $1 \mathrm{~mL} / \mathrm{min}$. DO and $\mathrm{pH}$ were measured using a handy meter (Mettler-Toledo, Switzerland).

\section{GC $\times$ GC-TOF-MS analysis}

Organic compounds from influent, anaerobic effluent, and aerobic effluent were extracted in triplicate using dichloromethane $\left(\mathrm{CH}_{2} \mathrm{Cl}_{2}\right)$ in alkaline, neutral, and acid phases separately and then pooled together, evaporated under nitrogen gas to approximately $1 \mathrm{~mL}$ and transferred to GC vials for analysis. Twelve standard compounds, viz., phenol, 2-methylphenol, 3methylphenol, (2,6)-dimethylphenol, (2,3)-dimethylphenol, (3,4)-dimethylphenol, quinolone, indole, aniline, isoquinoline, carbazole, and benzimidazole were purchased from Sigma Aldrich (Beijing, China). The organic compounds were determined by GC $\times$ GC-TOF-MS (Pegasus 4D Leco, USA) equipped with an Agilent $6890 \mathrm{~N}$ gas chromatograph, a secondary GC oven, and a dual stage jet modulator. Helium (99.9999\%), liquid nitrogen, and compressed air were used as carrier gas, coolant, and heat modulation gas, respectively. The modulation cycle time was $6 \mathrm{~s}$ and injector temperature was maintained at $250{ }^{\circ} \mathrm{C}$. Following splitless injection of a $1-\mu \mathrm{L}$ sample aliquot with constant current mode $(1 \mathrm{~mL} / \mathrm{min})$, the first dimension GC oven (column-RXI-5SIL MS, $30 \mathrm{~m} \times 250 \mu \mathrm{m} \times 0.25 \mu \mathrm{m}$ ) temperature was kept constant at $55^{\circ} \mathrm{C}$ for $1 \mathrm{~min}$, raised by $10{ }^{\circ} \mathrm{C} / \mathrm{min}$ to $160^{\circ} \mathrm{C}$ and held for $5 \mathrm{~min}$, then raised by $15^{\circ} \mathrm{C} / \mathrm{min}$ to $280^{\circ} \mathrm{C}$ and held for $10 \mathrm{~min}$. In the second dimension oven (Column D-RXI-1, $1.79 \mathrm{~m} \times 100 \mu \mathrm{m} \times 0.1 \mu \mathrm{m}$ ), the temperature was $5^{\circ} \mathrm{C}$ higher than that of the first oven. For TOF MS, we used an electron impact ionization source voltage of $70 \mathrm{eV}$ and detector voltage of $-1850 \mathrm{~V}$ with transmission line temperature of $300^{\circ} \mathrm{C}$ and ion source temperature of $220^{\circ} \mathrm{C}$. The data acquisition rate was $100 \mathrm{scans} / \mathrm{s}$ for a mass range of 45-500 amu. Data were processed and visualized on 2D chromatograms using LECO ChromaTOF software. Quantitation was based on calibration curves constructed by plotting peak areas (manually integrated) against concentration of standard compounds.

\section{DNA extraction}

Total DNA was extracted using the FastDNA ${ }^{\circledR}$ SPIN kit for soil (Qbiogene, Solon, OH, USA) facilitated with the FastPrep-24 bead beater system following the manufacturer's instructions. Extracted DNA sample was further purified using the Wizard ${ }^{\circledR}$ DNA Clean-up System (Promega, USA) to remove co-extracted organic impurities and improve the DNA quality. For a single sample, triplicate independent extractions were pooled together to maintain homogeneity and minimize bias. Both quantity and quality of DNA in the extracts were analyzed with a Nanodrop ND-1000 spectrophotometer (Thermo Scientific, Wilmington, DE, USA) and agarose $(1 \%)$ gel electrophoresis.

\section{Quantitative real-time PCR}

For each DNA sample, the bacterial 16S rRNA, archaeal 16S rRNA, and fungal $18 \mathrm{~S}$ rRNA genes were quantified with 
specific primers (Table S2) via the SYBR-Green method using the Applied Biosystems 7300 Real-Time PCR System (ABI, USA). Amplification was implemented in a $25-\mu \mathrm{L}$ reaction mixture consisting of $1 \times$ SYBR Green I, $1 \times$ Dye (Takara, China), $200 \mathrm{nM}$ of each primer, $0.5 \mathrm{mg} / \mathrm{mL}$ of bovine serum albumin (BSA), and $2 \mu \mathrm{L}$ of DNA template. The thermal program was one cycle at $95{ }^{\circ} \mathrm{C}$ for $30 \mathrm{~s}$, followed by 40 cycles consisting of (1) $95^{\circ} \mathrm{C}$ for $10 \mathrm{~s}$, (2) annealing temperature for $15 \mathrm{~s}$, (3) $72{ }^{\circ} \mathrm{C}$ for $15 \mathrm{~s}$, and $(4) 78^{\circ} \mathrm{C}$ for $26 \mathrm{~s}$ to collect the fluorescent signals.

Target genes containing standard plasmids were used to construct standard curves for real-time PCR assays. The plasmids were obtained by TA clones and extracted from positive clones using a TIANpure Mini Plasmid kit (Tiangen, China). The quantities $(\mathrm{ng} / \mu \mathrm{L})$ of extracted plasmids were determined using a Nanodrop spectrophotometer (ND-1000; Thermo Fisher Scientific, USA) and the copy concentrations (copies $/ \mu \mathrm{L}$ ) were calculated as described by McKew and Smith (2010). Tenfold serial dilutions of known copy numbers of standard plasmid DNA were subjected to qPCR in triplicate to generate standard curves. The curves were based on five to seven orders of magnitude. The correlation coefficients $\left(R^{2}\right)$ for standard curves and amplification efficiencies $\left[E=\left(10^{-1 / \text { slope }}-1\right) \times 100 \%\right]$ based on curve slopes were calculated to ensure reliable amplification. The $R^{2}$ values for all three curves were over 0.99 and $E$ was between 104 and $108 \%$. The specificity of the PCR was also assured by melting curves and gel electrophoresis.

\section{4 pyrosequencing}

\section{PCR amplification and purification}

For pyrosequencing, six samples were selected (three from the aerobic and three from the anaerobic reactor) on days 125, 228, and 276. The DNA samples were PCR amplified (ABI GeneAmp ${ }^{\circledR} 9700$ type, CA, USA) to obtain the amplicons of bacterial and archaeal 16S rRNA genes and fungal ITS regions. The primer sequences and annealing temperatures for PCR are given in Table S2. Barcodes that allow sample multiplexing in the mixed reaction during pyrosequencing were incorporated between the 454 adapter and forward primers. The PCR reaction was carried out in a $20-\mu \mathrm{L}$ volume containing $4 \mu \mathrm{L}$ of $5 \times$ FastPfu Buffer, $2 \mu \mathrm{L}$ of $2.5 \mathrm{mM}$ dNTPs, $0.8 \mu \mathrm{L}$ of each primer $(5 \mu \mathrm{M}), 0.8 \mu \mathrm{L}$ of TransStartFastPfu Polymerase (TransGen AP221-02), and $10 \mathrm{ng}$ of template DNA. The mixtures were initially denatured at $95{ }^{\circ} \mathrm{C}$ for 2 min and then amplified with 25 cycles (bacterial $16 \mathrm{~S}$ rRNA) or 30 cycles (archaeal 16S rRNA genes and fungal ITS) at (1) $95{ }^{\circ} \mathrm{C}$ for $30 \mathrm{~s}$; (2) annealing temperature for $30 \mathrm{~s}$; (3) $72{ }^{\circ} \mathrm{C}$ for $30 \mathrm{~s}$, and a final extension at $72{ }^{\circ} \mathrm{C}$ for $5 \mathrm{~min}$. Triplicate PCR products of the same sample were assembled into a PCR tube. The PCR products were electrophoresed on $2 \%$ agarose gel and purified using an AxyPrepDNA Gel
Extraction Kit (AXYGENA Corporation). The length of the amplicon, including the barcode and 454 primers, was $\sim 596 \mathrm{nt}$.

\section{Pyrosequencing}

The purified PCR products of the bacterial, archaeal, and fungal community marker genes were sequenced by pyrosequencing reaction using a 454 Life Sciences Genome Sequencer FLX (Roche Diagnostics, Indianapolis, IN, USA). Due to the poor quality of some PCR products, one sample (125 days, anaerobic sludge) was dropped from further analysis for archaeal 16S rRNA gene amplicons.

The raw pyrosequencing data generated by this study were deposited in the NCBI database with SRP number SRP070737.

\section{Sequence analyses}

Following the completion of sequencing, Mothur software (Schloss et al. 2009) was applied to analyze raw pyrosequencing data reads. The raw reads with quality scores $\leq 20$ were filtered out. The completeness of barcode sequences was examined and multiplexed reads were assigned to specific samples based on nucleotide barcodes. The sequence reads were further filtered following the criteria that the reads (1) did not match the proximal PCR primer at the level of even a single base bias, (2) had a sequence length shorter than $200 \mathrm{bp}$ for bacteria and archaea and 400 bp for fungi (Liu et al. 2012), (3) had a sequence of a high single base repeat region (homopolymers longer than six nucleotides), (4) contained single or multiple ambiguous base(s), and (5) signaled as a chimeric sequence (generated in PCR amplification) detected by UCHIME (http://drive5.com/uchime). After filtration was complete, the valid sequences were trimmed and aligned using the standard Silva database (version SSU111, http:// www.arb-silva.de/) with k-mer searching (http://www.mothur. org/wiki/Align.seqs). The effective sequences were then clustered into operational taxonomic units (OTUs) with $97 \%$ or higher similarity on the furthest neighbor algorithm (http:// www.mothur.org/wiki/Cluster). Mothur software was again used to classify (http://www.mothur.org/wiki/Classify.seqs) the taxonomy to phylum, class, order, family, and genus level via the aforementioned Silva taxonomy database and the Naïve Bayesian Classifier algorithm (Wang et al. 2007) with a confidence threshold of $80 \%$ bootstrap (Ma et al. 2013).

The depth of sequencing for each sample and target marker gene was assessed by generating rarefaction curves with $97 \%$ similarity of OTUs using Mothur software. Community richness was estimated by Chaol (http://www.mothur.org/wiki/ Chao) and abundance-based coverage estimator (ACE, http://www.mothur.org/wiki/Ace) indices, and community diversity was estimated by the Shannon (http://www.mothur. org/wiki/Shannon) and Simpson (http://www.mothur.org/ wiki/Simpson) indices. 


\section{Results}

\section{Performance of pollutant removal of the treatment system}

Bioreactor performance was monitored over 300 days, as shown in Fig. 2. On average, the anaerobic bioreactor removed approximately one third of organic matter $(32.7 \%$ COD and $34.2 \%$ TOC), but in combination with the aerobic bioreactor overall removal of COD and TOC were 81.8 and $85.6 \%$, respectively (Fig. 2a, b; Table S1). The anaerobic reactor removed more than half of total phenols ( $54.0 \%$ ), while the aerobic reactor removed almost all the remaining phenols (99.9 \%) (Fig. 2c; Table S1). While total nitrogen was almost unchanged during treatment (Fig. 2d; Table S1), ammonia-nitrogen $\left(\mathrm{NH}_{4}{ }^{+}-\mathrm{N}\right)$ and sulfate $\left(\mathrm{SO}_{4}{ }^{2-}\right)$ were markedly increased during the aerobic process, with effluent concentrations of $149.5 \pm 27.1 \mathrm{mg} / \mathrm{L}$ and $1512.5 \pm 320.7 \mathrm{mg} / \mathrm{L}$, respectively (Fig. 2e, f; Table S1). During the whole period, no methane formation was observed. In spite of the stable performance of the combined system, an additional physicochemical approach may be required for further treatment considering the relatively high effluent COD $(520.1 \pm 73.1 \mathrm{mg} / \mathrm{L})$ and TOC $(112.1 \pm 21.8 \mathrm{mg} / \mathrm{L})$.
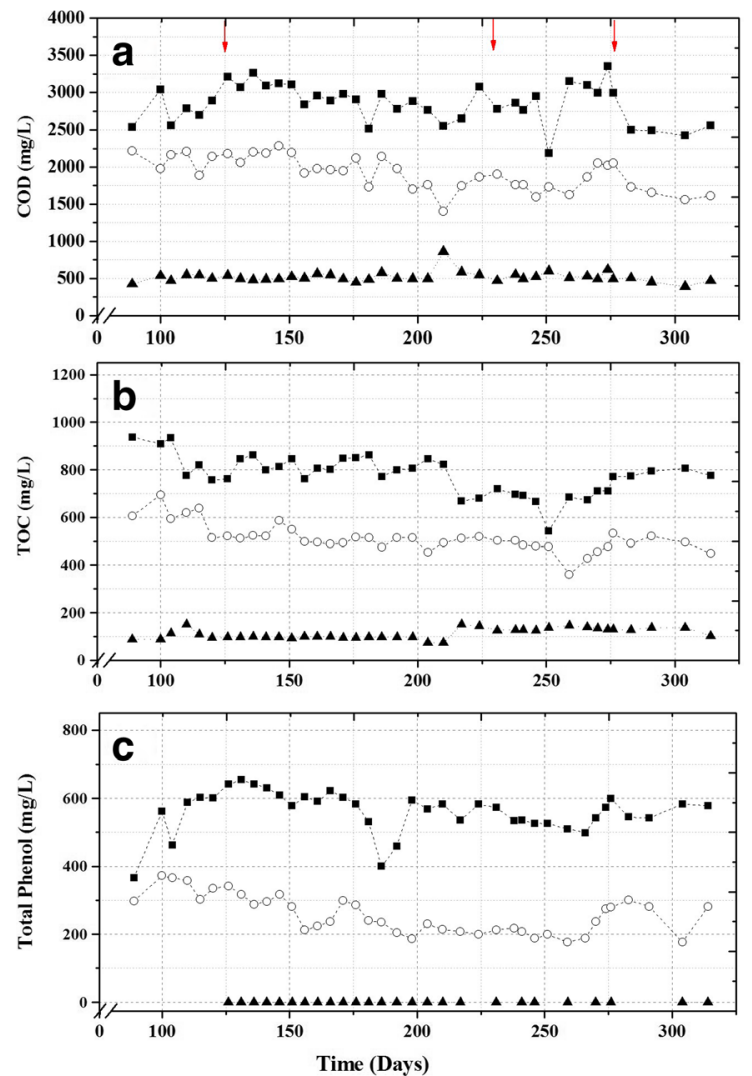

Fig. 2 Performances of anaerobic and aerobic bioreactors during coking wastewater treatment. a Chemical oxygen demand (COD). b Total organic carbon (TOC). $\mathbf{c}$ Total phenol. d Total nitrogen. e Ammonia nitrogen. $\mathbf{f}$ Sulfate $\left(\mathrm{SO}_{4}{ }^{2-}\right)$ concentrations. Closed squares indicate the measurements of influent coking wastewater, open circles indicate
Table 1 shows the GC $\times$ GC-TOF-MS analysis results for the six phenolic derivatives (phenol, 2-methylphenol, 3methylphenol, (2,6)-dimethylphenol, (2,3)-dimethylphenol, and $(3,4)$-dimethylphenol) and six NHCs (quinolone, indole, aniline, isoquinoline, carbazole, and benzimidazole). Anaerobic treatment removed individual organic compounds with removal efficiencies ranging from 0.0 to $84.6 \%$, giving an average removal of phenolic derivatives and NHCs of 58.4 and $58.6 \%$, respectively. The combination of anaerobic and aerobic treatment resulted in almost complete removal of these compounds.

As shown in Fig. 2, although anaerobic treatment was not effective, the combined system was quite efficient for the removal of $\mathrm{SCN}^{-}(98.2 \%)$ and $\mathrm{CN}^{-}(85.4 \%)$ (Table S1). Degradation of $\mathrm{SCN}^{-}, \mathrm{CN}^{-}$, and other nitrogen and sulfur heterocyclic organic compounds was responsible for the release of ammonium and sulfate (Felföldi et al. 2010; Staib and Lant 2007; Vazquez et al. 2006; Maranon et al. 2008; Gai et al. 2007). Oxidation of sulfides and thiosulfate (Shoji et al. 2014) may have also contributed to the increased concentration of inorganic sulfate in the aerobic effluent.
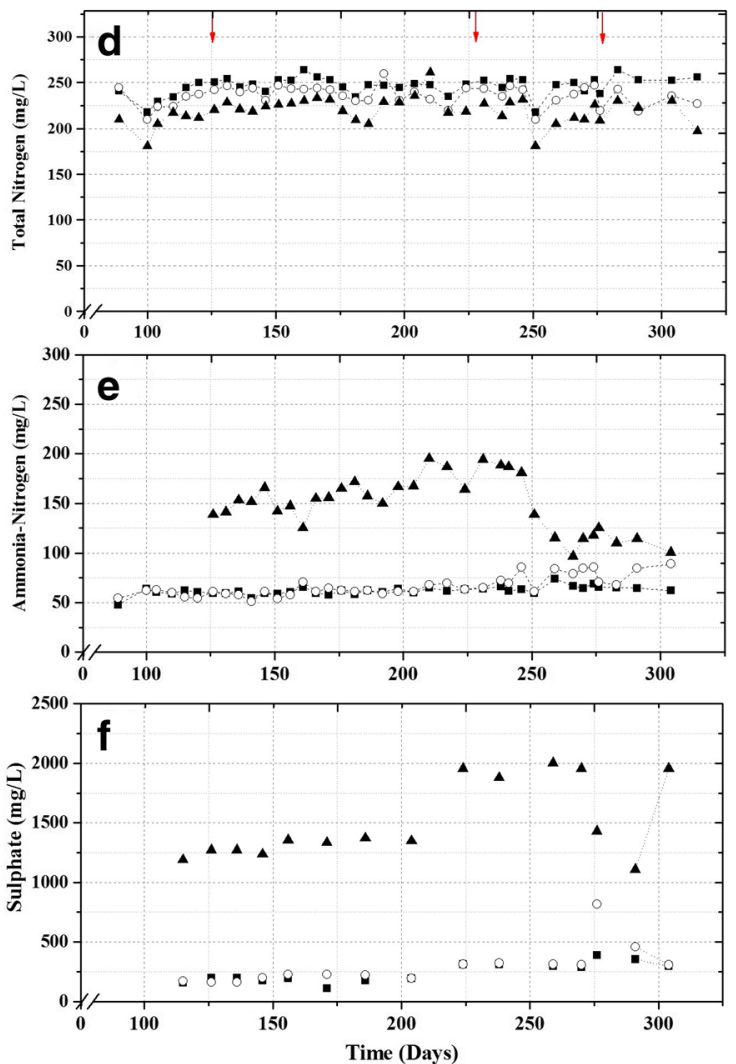

measurements of anaerobic effluent, and closed triangles indicate measurements of aerobic effluent. All measurements are expressed in milligrams per liter. Vertical downward red arrows indicate the sampling time (125th, 228th, and 276th day of operation) of sludge collection for 16S rRNA and 18S rRNA gene amplicon pyrosequencing 
Table 1 Removal of organic compounds in coking wastewater as detected by GC $\times$ GC-TOF-MS

\begin{tabular}{|c|c|c|c|c|c|c|}
\hline \multirow[t]{2}{*}{ Number } & \multirow[t]{2}{*}{ Organic pollutants } & \multicolumn{3}{|l|}{ Concentration $(\mathrm{mg} / \mathrm{L})$} & \multicolumn{2}{|c|}{ Average removal $(\%)$} \\
\hline & & Influent wastewater & Anaerobic effluent & Aerobic effluent & Anaerobic & Overall \\
\hline 1 & Phenol & $355.1 \pm 5.0$ & $146.1 \pm 6.2$ & nd & 58.9 & $\sim 100$ \\
\hline 2 & 2-Methylphenol & $22.3 \pm 2.3$ & $11.1 \pm 0.5$ & nd & 50.2 & $\sim 100$ \\
\hline 3 & 3-Methylphenol & $56.6 \pm 3.3$ & $23.5 \pm 3.1$ & nd & 58.5 & $\sim 100$ \\
\hline 4 & 2,3-Dimethylphenol & $0.5 \pm 0.0$ & $0.5 \pm 0.0$ & nd & 0.0 & $\sim 100$ \\
\hline 5 & 3,4-Dimethylphenol & $2.1 \pm 0.1$ & $0.6 \pm 0.1$ & nd & 71.4 & $\sim 100$ \\
\hline 6 & 2,6-Dimethylphenol & $1.3 \pm 0.1$ & $0.2 \pm 0.0$ & nd & 84.6 & $\sim 100$ \\
\hline Total phenol derivative compounds & & 437.9 & 182.0 & 0 & 58.4 & $\sim 100$ \\
\hline 7 & Aniline & $1.0 \pm 0.1$ & $0.4 \pm 0.0$ & nd & 60.0 & $\sim 100$ \\
\hline 8 & Quinoline & $2.2 \pm 0.1$ & $0.6 \pm 0.0$ & nd & 72.7 & $\sim 100$ \\
\hline 9 & Isoquinoline & $0.4 \pm 0.0$ & $0.3 \pm 0.0$ & nd & 25.0 & $\sim 100$ \\
\hline 10 & Indole & $7.7 \pm 1.5$ & $2.8 \pm 0.4$ & nd & 63.6 & $\sim 100$ \\
\hline 11 & Benzimidazole & $1.0 \pm 0.0$ & $0.8 \pm 0.1$ & nd & 20.0 & $\sim 100$ \\
\hline 12 & Carbazole & $0.5 \pm 0.0$ & $0.4 \pm 0.0$ & nd & 20.0 & $\sim 100$ \\
\hline Total nitrogenous heterocyclic compounds & 12.8 & 5.3 & 0 & 58.6 & $\sim 100$ & \\
\hline
\end{tabular}

nd not detected (concentration below the detection limit)

\section{Microbial population analyses}

Total bacterial population as estimated by qPCR (Table S3) revealed that copy numbers of $16 \mathrm{~S}$ rRNA genes per microliter of DNA ranged from 1.2 to $2.1 \times 10^{5}$ and 1.5 to $9.2 \times 10^{6}$ in anaerobic and aerobic bioreactors, respectively. The archaea and fungi represented only minor populations in the anaerobic and aerobic bioreactors, respectively, with ratios of copy numbers of their phylogenetic marker genes to bacterial $16 \mathrm{~S}$ rRNA genes of $1.8-3.2 \times 10^{-2}$ and $0.3-3.1 \times 10^{-2}$.

\section{Richness and phylogenetic diversity indices}

Barcoded pyrosequencing of phylogenetic marker gene amplicons explores the diversity and composition of microbial communities at a high level of resolution (Sogin et al. 2006). The microbial diversity profile obtained by 454 pyrosequencing of bacterial 16S rRNA genes revealed a total of 72,069 effective sequence reads (average length $472.7 \mathrm{bp}$ ) from six sludge samples assigned to 2318 OTUs (97 \% similarity). A total of 17,949 sequence reads of fungal ITS region genes (average size $435.2 \mathrm{bp}$ ) obtained from three aerobic sludge samples were assigned to 137 OTUs. In two samples of anaerobic sludge, a total of 7650 sequences (average length of $443 \mathrm{bp}$ ) were obtained and assigned to 67 archaeal OTUs (Table S4). Rarefaction curves (Fig. S1) revealed approximate saturation for all microbial domains in all samples, indicating that all samples were sequenced in depth (Hughes and Hellmann 2005). Microbial community richness as determined by ACE and Chao indices (Table S4) was higher for the bacterial community compared with that of the archaea and fungi communities in anaerobic and aerobic sludge samples, respectively. Similar patterns of diversity complexity (alpha-diversity) were found, as determined by the Shannon index $(H)$.

\section{Bacterial communities}

The16S rRNA gene sequences classified against the Silva data base (97\% similarity) revealed taxonomic affiliations to 21 bacterial phyla. In the anaerobic reactor, Proteobacteria showed the highest relative abundance (64.2-76.0\%), followed by Actinobacteria (3.1-14.1\%), Firmicutes (11.9-13.5\%), Chloroflexi (3.6-5.2 \%), and Bacteroides (3.3-4.7\%). In the aerobic reactor, the relative abundance of Proteobacteria was highest (90.2-93.4 \%), followed by Bacteroides (1.8-4.6\%), Actinobacteria (1.9-3.4 \%), and Firmicutes (0.4-4.3\%) (Fig. S2). Proteobacteria in both reactors consisted predominantly of classes Betaproteobacteria (34.4-70.1\%) and Alphaproteobacteria (10.9-31.7 \%) (Fig. S3). In addition, Clostridia (10.7-12.8\%), Anaerolineae (3.4-5.1\%), and Bacteroidia (2.7-4.4\%) in anaerobic sludge and Flavobacteria (1.1-4.0 \%) and Bacilli (0.3-3.7 \%) in aerobic sludge had comparatively higher abundances. At the lower taxa level, of the 189 genera identified (Fig. 3b; Table S5), the most dominant genera in anaerobic sludge were Ottowia (14.1-46.7\%), Soehngenia (3.0-8.2\%), Corynebacterium (0.9-12.0\%), Advenella (0.6-3.2\%), Longilinea (2.6$3.5 \%$ ), Clostridium (1.3-2.3\%), and Proteiniphilum (1.2$2.3 \%)$. In aerobic sludge, however, the most dominant genera were Thiobacillus (6.6-43.6 \%), Diaphorobacter (5.1$13.0 \%$ ), Comamonas (0.2-11.1\%), Ottowia (4.3-7.4\%), 
Bosea (0.3-6.5\%), Arenimonas (0.5-5.6\%), Brevundimonas (0.1-3.6\%), Sphingopyxis (1.4-2.2\%), and Sphingosinicella (1.2-1.6\%). A difference was observed among bacterial communities of aerobic sludge samples at the genera level (Fig. 3a), mainly with a much lower abundance of Thiobacillus on day 125 (first sample), probably due to its slow growth rate.

\section{Archaeal communities}

Almost all phylogenetic groups of the archaeal community belonged to phylum Euryarchaeota (96.2-98.3 \%), primarily in two classes Methanomicrobia (73.0-75.7\%) and Methanobacteria (20.2-20.9\%). At the genus level, Methanosarcina (41.7-44.3\%) exhibited the highest abundance, followed by Methanobacterium (19.8-20.3\%), Methanomethylovorans (16.6-20.6\%), and Methanosaeta (4.7-6.3\%) (Fig. 4a; Table S6).

\section{Fungal communities}

Though often neglected, fungi are important components of the aerobic sludge community. In the present study, phylum Basidiomycota (63.9-87.1\%) accounted for the majority of the fungal community. The genus Trichosporon (62.9$88.3 \%$ ) was the dominant yeast (Fig. 4b; Table S7) in the aerobic sludge, while $10.2-34.5 \%$ of fungal OTUs remained unclassified. Trichosporon was previously isolated and applied for phenol and PAH degradation (Alexieva et al. 2008).

\section{Discussion}

It is known that phenols, $\mathrm{NHCs}, \mathrm{SCN}^{-}$, and $\mathrm{CN}^{-}$represent the major components of COD in CWW (Ashmore et al. 1967; Li et al. 2003). As shown in Fig. 2 and Table 1, anaerobic treatment removed over one third of COD and TOC, and more than half of phenolic derivatives and NHCs, showing that the anaerobic processes could play an important role in the treatment of CWW. The results of this study are consistent with those of Wang et al. (2011) and Zhu et al. (2016) who showed 20-30\% COD removal by mesophilic anaerobic treatment. The removal of total phenols $(54.0 \%)$ and phenolic derivatives (58.4\%) was achieved in the present study, and were considerably higher than that achieved in previous studies (Wang et al. 2011, 20-30 \%; Zhu et al. 2016, $18.0 \%$ ), which might be partly due to the longer HRT (42 h) applied in this study. In addition, the removal of NHCs reached $58.6 \%$, demonstrating that both phenols and NHCs could be partly removed through anaerobic treatment. Sharma and Philip (2015) also reported detoxification of a synthetic mixture of pollutants in CWW by anaerobic treatment, leading to significant removal of $\mathrm{COD}$ and $\mathrm{CN}^{-}$in downstream reactors. However, in the present study, $\mathrm{SCN}^{-}$and $\mathrm{CN}^{-}$were not
Fig. 3 Bacterial community composition with relative abundances of each genus in anaerobic and aerobic sludge. a Hierarchical clustering analysis shows the dissimilarities of sludge samples based on relative abundance of bacterial genera. $\mathbf{b}$ Bar diagram represents relative abundances of genus-level phylogenetic groups based on 454-pyrosequenced 16S rRNA gene amplicons (classification based on Silva taxonomic database) showing structures of bacterial communities in each sample

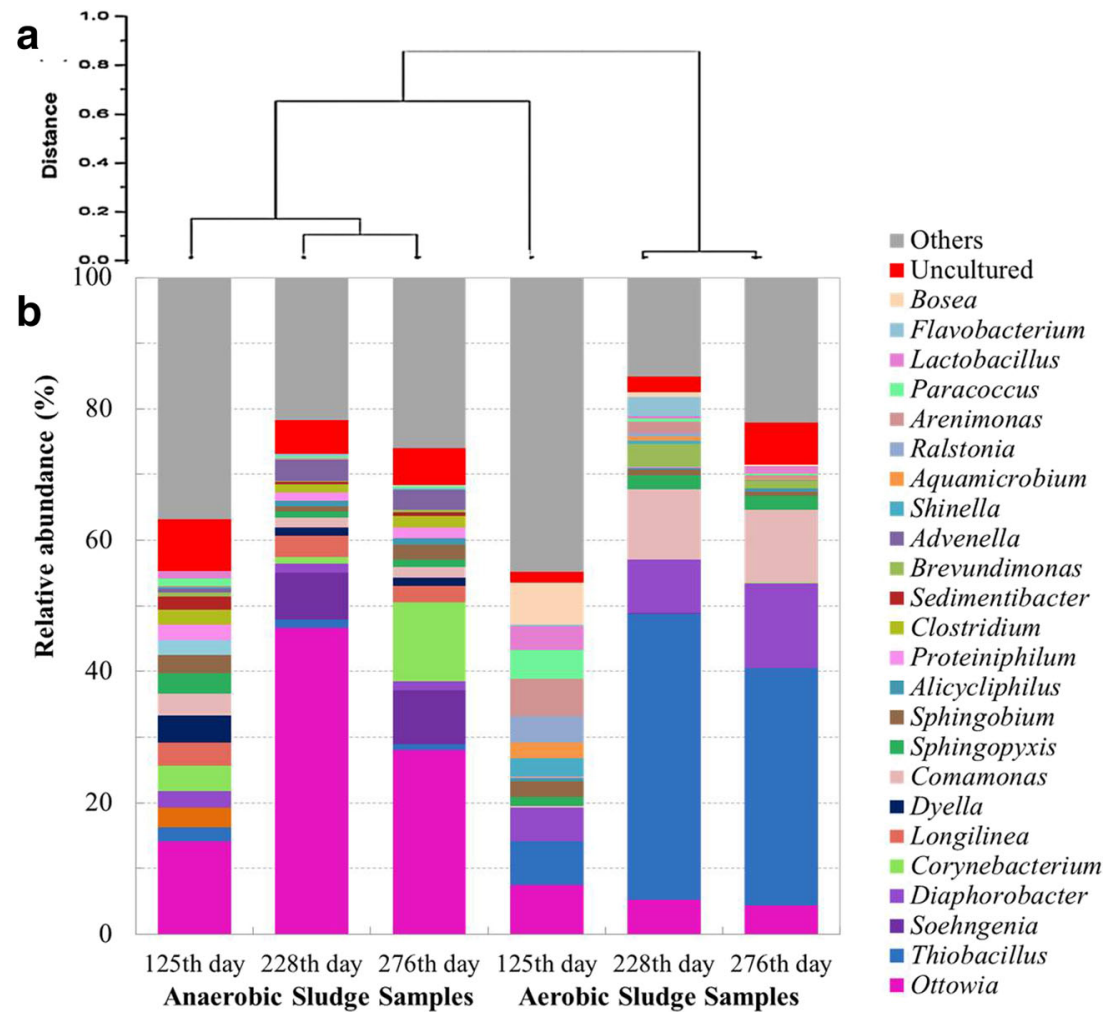




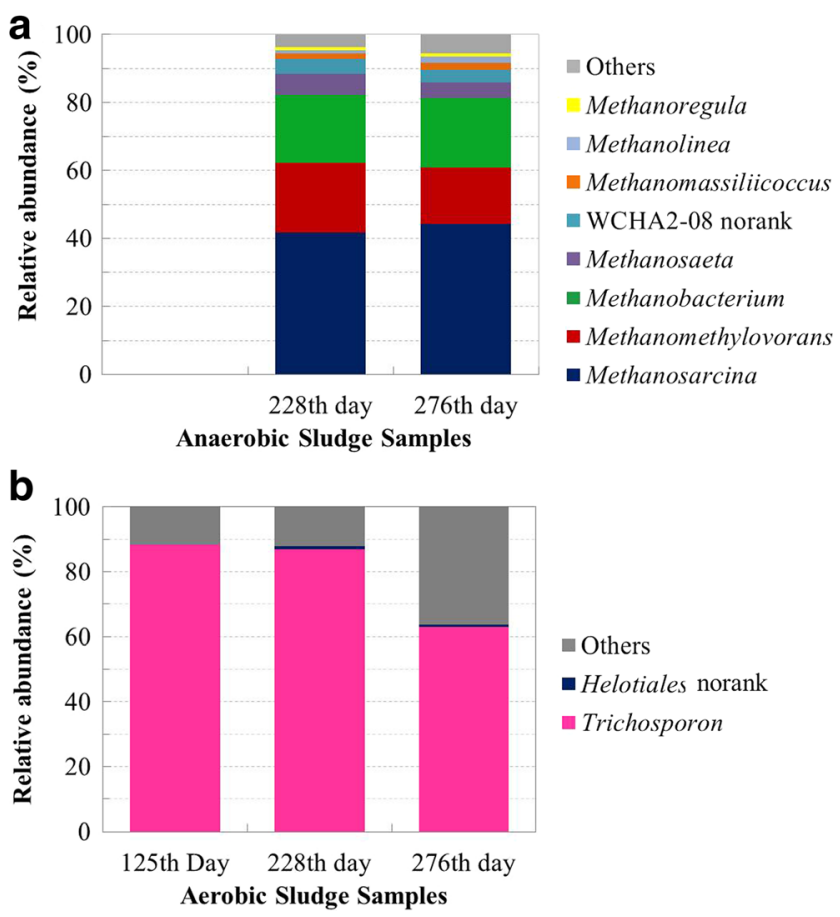

Fig. 4 Composition and relative abundances of a archaeal genera in anaerobic sludge samples and $\mathbf{b}$ fungal genera in aerobic sludge samples. Bar diagrams represent relative abundances of genus-level phylogenetic groups based on 454-pyrosequenced a 16S rRNA gene amplicons of archaea and $\mathbf{b}$ ITS region amplicons of fungi showing respective community structures in each sample

removed significantly by anaerobic treatment. Table 1 and Table S1 reveal that the combined anaerobic-aerobic system removed almost all phenol derivatives and NHCs along with significant removal of COD (81.8\%), $\mathrm{SCN}^{-}(98.2 \%)$, and $\mathrm{CN}^{-}(85.4 \%)$. The overall removal efficiency achieved in this study is in agreement with that obtained in previous studies (Zhu et al. 2016; Sharma and Philip 2015; Jin et al. 2013; Lai et al. 2008; Maranon et al. 2008), showing COD, total phenol, and $\mathrm{SCN}^{-}$removals of $63.0-86.5 \%, 98.0-100.0 \%$, and 90.0 $98.0 \%$, respectively, in integrated anaerobic-anoxic-aerobic treatment systems with or without sludge recirculation. Thus, the combined process not only significantly saved aeration energy but ensured better system stability when encountering fluctuations in wastewater compositions and toxic load (Chakraborty and Veeramani 2002).

In spite of the removal of COD in the anaerobic reactor, methane gas formation was not observed during the whole period, which was in accordance with the low gene copy number ratio of archaea to bacteria $\left(1.8-3.2 \times 10^{-2}\right)$. Wang et al. (2011) also noted complete inhibition of methane production in the mesophilic anaerobic reactor treating Lurgi coal gasification wastewater. This might be due to $\mathrm{CN}^{-}$in CWW, which is reported to inhibit methanogenesis (Fedorak et al. 1986). It is interesting that Methanosarcina was the dominant archaea in the anaerobic bioreactor; however, its role in the anaerobic sludge remains unclear.
In the aerobic process, $\mathrm{SCN}^{-}$degradation and ammonification of NHCs was coupled with increased concentration of ammonia-nitrogen in the final effluent (Staib and Lant 2007; Vazquez et al. 2006; Felföldi et al. 2010), while total nitrogen (TN) remained approximately constant throughout the process. The absence of nitrifying bacteria in the aerobic sludge (Table S5) might be due to insufficient HRT (72 h) or an inhibitory effect of toxic compounds (Kim et al. 2013). Ma et al. (2015a) also reported relatively low abundance $(<1 \%)$ of ammonia and nitrite oxidizing bacteria in activated sludge of CWW treatment plants. Increased HRT, a maintained C/N ratio, and recycling of sludge may improve ammonia removal (Chakraborty and Veeramani 2006; Lai et al. 2008). However, the factors associated with maintenance of nitrifying populations in CWW sludge should be further investigated.

Biodegradation relies on the composition and activity of microbial communities in sludge. Similar to the results of this study, the dominance of Betaproteobacteria (higher taxa) has been frequently observed in phenol degradation systems, including CWW (Manefield et al. 2005; Zhu et al. 2013, 2016; Ma et al. 2015a; Wang et al. 2015b) petroleum refinery, pharmaceutical (Ibarbalz et al. 2013), and municipal (Zhang et al. 2012; Wang et al. 2012; Hai et al. 2014; Shu et al. 2015) wastewater treatment plants, as well as in different types of bioreactors (Wagner and Loy 2002). This highlights the rapid acclimatization and metabolic significance of Betaproteobacteria in the removal of a wide range of pollutants, including phenolic compounds from CWW.

Among the detected genera in the present study, most dominant ones were assumed to be associated with the biodegradation of organic and inorganic pollutants (Table S8). In the anaerobic sludge, the facultative aerobic Gram-negative bacterium Ottowia was the most abundant genus, which differed from previous studies (Wang et al. 2015b; Zhu et al. 2016). Though Ottowia has been isolated from activated sludge treating CWW wastewater (Felfoldi et al. 2011; Cao et al. 2014; Geng et al. 2014), its presence at such a high abundance in anaerobic sludge was not reported previously. The presence of Ottowia together with Advenella (Wang et al. 2014; Ghosh et al. 2011), Corynebacterium (Dalal et al. 2012; Guo et al. 2015), and Sphingobium (Kertesz and Kawasaki 2010) might be associated with the removal of phenols, NHCs as well as PAHs under the anaerobic conditions (Table S8). Soehngenia, the second most abundant anaerobic bacterium in this study, was previously reported to degrade benzaldehyde (Parshina et al. 2003), an intermediate in anaerobic phenol degradation (Sharma and Philip 2015). Hydrolytic fermentative acidogenic activity in anaerobic bioreactors is likely controlled by strict anaerobic bacteria like Longilinea, Clostridium, and Proteiniphilum (Yamada et al. 2007; Kohda et al. 1997; Letowski et al. 2001; Chen and Dong 2005; Larsen et al. 2009) and facultative aerobic bacteria such as Corynebacterium (Kampfer et al. 2009). 
In the aerobic sludge, the high abundances of Thiobacillus, Comamonas, Diaphorobacter, Ottowia, and Weeksella (Table S8), which reportedly degrade several phenol and $\mathrm{SCN}^{-}$compounds (Felföldi et al. 2010; Beller et al. 2006; Klankeo et al. 2009; Yuste et al. 2000), were in accordance with the significant removal of pollutants in the final effluent. As referred in Table S8, the significant presence of PAHdegrading bacteria like Comamonas (Goyal and Zylstra 1996) and Diaphorobacter (Klankeo et al. 2009) indicated the removal of corresponding pollutants in aerobic sludge leading to detoxification of CWW (Zhang et al. 2013). The high abundances of NHC-degrading bacteria Brevundimonas, Sphingopyxis, Sphingosinicella (Wang et al. 2015a; Stolz 2009; Baik et al. 2013), and Comamonas (Felföldi et al. 2010; Zhang et al. 2015) also tallied with the complete disappearance of NHCs in the final effluent in this study. The NHCutilizing bacteria detected in CWW treating sludge exhibit considerable potential for biotechnological applications. For instance, Comamonas, Pusillimonas, and Sphingopyxis utilize indole as a sole source of carbon (Ma et al. 2015b) and can biosynthesize indigo from indole (Zhang et al. 2015). Chemolithotrophic sulfur oxidizing bacteria Thiobacillus, Comamonas, and Diaphorobacter can also oxidize thiosulfate (Shoji et al. 2014; Narayan et al. 2010; Pham et al. 2009), thereby contributing increased concentrations of sulfate in aerobic effluent. Ma et al. (2015a) and Zhu et al. (2016) also observed a higher abundance of Thiobacillus and Comamonas in aerobic activated sludge treating CWW. Additionally, certain species of detected bacteria, such as Comamonas and Ottowia, are floc-forming bacteria (Tago and Yokota 2004; Felföldi et al. 2010) and might play significant roles in active sludge structure formation, and hence contribute to the stability of the aerobic system.

Although fungi have been encountered in wastewater treatment plants and found to biodegrade pollutants (Yang et al. 2011), their roles in CWW treatment systems are often neglected. In this study, oleaginous yeast Trichosporon was the only dominant fungi in the aerobic sludge. Trichosporon is known for its potential to degrade phenol, cresol, aliphatic, and aromatic hydrocarbons (DeRito and Madsen 2009; Alexieva et al. 2008). To our knowledge, however, little has been reported on the fungal community in aerobic systems treating CWW.

In this study, abundant and probably the active microbial genera were different (Figs. 3 and 4) as compared to those in the sludge treating municipal sewage (Zhang et al. 2012) and other industrial wastewaters (Ibarbalz et al. 2013) that may be credited to complex nature of CWW as shown in previous literatures (Zhang et al. 2013; Zhao et al. 2014; Hou et al. 2015) and also in this study. Interestingly, bacterial and fungal community compositions in the sludge were in accordance to bioreactor performance removing majority of organic and toxic pollutants. These results provide evidence that the relative abundance of specific microbial groups including bacterial and fungal genera is possibly correlated with their functional potential to degrade pollutants of CWW. The dominant microbial genera obtained in this study could be potential tool for bioremediation of CWW.

In conclusion, the results presented herein suggest that sequential anaerobic-aerobic processes could be a simple and less energy intensive alternate for the removal of major pollutants like phenolics, NHCs, $\mathrm{SCN}^{-}$, and $\mathrm{CN}^{-}$in CWW. The most abundant bacterial genera, namely, Ottowia, Soehngenia, Comamonas, Thiobacillus, Diaphorobacter, and the yeast Trichosporon, might play key roles in the biodegradation of the CWW pollutants. The results of the present study were acquired through analysis of pyrosequenced phylogenetic marker gene amplicons retrieved from community DNA. There is a further need to investigate microbial functional community structure and interactions to explore the functional ecology of the complex niches formed in sludge systems treating CWW.

Acknowledgments This study was funded by the State Hi-tech Research and Development Project of the Ministry of Science and Technology, People's Republic of China (2012AA063401) and Tianjin Science and Technology Project (15YFYSSF00040).

\section{Compliance with ethical standards}

Conflict of interest The authors declare they have no competing interests.

Ethical approval This article does not contain any studies with human participants or animals performed by any of the authors.

\section{References}

Alexieva Z, Gerginova M, Manasiev J, Zlateva P, Shivarova N, Krastanov A (2008) Phenol and cresol mixture degradation by the yeast Trichosporon cutaneum. J Ind Microbiol Biotechnol 35(11): 1297-1301. doi:10.1007/s10295-008-0410-1

APHA (2005) Standard methods for the examination of water and wastewater, 21st edn. American Public Health Association, Washington

Ashmore AG, Catchpole JR, Cooper RL (1967) The biological treatment of carbonization effluents I. Investigation into treatment by the activated sludge process. Water Res 1:605-624. doi:10.1016/00431354(67)90043-7

Bai Y, Sun Q, Zhao C, Wen D, Tang X (2009) Simultaneous biodegradation of pyridine and quinoline by two mixed bacterial strains. Appl Microbiol Biotechnol 82(5):963-973. doi:10.1007/s00253009-1892-0

Baik KS, Choe HN, Park SC, Hwang YM, Kim EM, Park C, Seong CN (2013) Sphingopyxis rigui sp. nov. and Sphingopyxis wooponensis sp. nov., isolated from wetland freshwater, and emended description of the genus Sphingopyxis. Int J Syst Evol Microbiol 63:1297-1303. doi:10.1099/ijs.0.044057-0

Beller HR, Chain PSG, Letain TE, Chakicherla A, Larimer FW, Richardson PM, Coleman MA, Wood AP, Kelly DP (2006) The genome sequence of the obligately chemolithoautotrophic, facultatively anaerobic bacterium Thiobacillus denitrificans. J Bacteriol 188(4):1473-1488. doi:10.1128/JB.188.4.1473-1488.2006 
Cao J, Lai Q, Liu Y, Li G, Shao Z (2014) Ottowia beijingensis sp. nov., isolated from coking wastewater activated sludge, and emended description of the genus Ottowia. Int J Syst Evol Microbiol 64(3): 963-967. doi:10.1099/ijs.0.054015-0

Chakraborty S, Veeramani H (2002) Anaerobic-anoxic-aerobic sequential degradation of synthetic wastewaters. Appl Biochem Biotechnol 102-103:443-451. doi:10.1385/ABAB:102-103:1-6:443

Chakraborty S, Veeramani H (2006) Effect of HRT and recycle ratio on removal of cyanide, phenol, thiocyanate and ammonia in an anaerobic-anoxic-aerobic continuous system. Process Biochem 41(1):96-105. doi:10.1016/j.procbio.2005.03.067

Chen S, Dong X (2005) Proteiniphilum acetatigenes gen. nov., sp. nov., from UASB reactor treating brewery wastewater. Int J Syst Evol Microbiol 55:2257-2261. doi:10.1099/ijs.0.63807-0

Chen H, Yang G, Feng Y, Shi C, Xu S, Weiping Cao W, Xiaoming Zhang X (2012) Biodegradability enhancement of coking wastewater by catalytic wet air oxidation using aminated activated carbon as catalyst. Chem Eng J 198-199:45-51. doi:10.1016/j.cej.2012.05.082

Dalal S, Panigrahi DP, Randhawa GS, Dubey RC (2012) catA gene in potential Corynebacterium strain is responsible for its efficiency in phenol bioremoval. Polycycl Aromat Compd 32(4):423-428. doi: 10.1080/10406638.2011.645267

DeRito CM, Madsen EL (2009) Stable isotope probing reveals Trichosporon yeast to be active in situ in soil phenol metabolism. ISME J 3:477-485. doi:10.1038/ismej.2008.122

Fedorak PM, Roberts DJ, SE H (1986) The effects of cyanide on the methanogenic degradation of phenolic compounds. Water Res 20(10):1315-1320

Felfoldi T, KekI Z, Sipos R, Marialigeti K, Tindall BJ, Schumann P, Toth EM (2011) Ottowia pentelensis sp. nov., a floc-forming betaproteobacterium isolated from an activated sludge system treating coke plant effluent. Int J Syst Evol Microbiol 61(9):21462150. doi:10.1099/ijs.0.020818-0

Felföldi T, Székely AJ, Gorál R, Barkács K, Scheirich G, András J, Rácz A, Márialigeti K (2010) Polyphasic bacterial community analysis of an aerobic activated sludge removing phenols and thiocyanate from coke plant effluent. Bioresour Technol 101(10):3406-3414. doi:10. 1016/j.biortech.2009.12.053

Gai Z, Yu B, Li L, Wang Y, Ma C, Feng J, Deng Z, Xu P (2007) Cometabolic degradation of dibenzofuran and dibenzothiophene by a newly isolated carbazole-degrading Sphingomonas sp. strain. Appl Environ Microbiol 73(9):2832-2838. doi:10.1128/AEM. 02704-06

Geng S, Pan X, Mei R, Wang Y, Sun J, Liu X, Tang Y, Wu X (2014) Ottowia shaoguanesis sp. nov., isolated from coking wastewater. Curr Microbiol 68:324-329. doi:10.1007/s00284-013-0481-8

Ghosh W, George A, Agarwal A, Raj P, Alam M, Pyne P, Das Gupta SK (2011) Whole-genome shotgun sequencing of the sulfur-oxidizing chemoautotroph Tetrathiobacter kashmirensis. J Bacteriol 193(19): 5553-5554. doi:10.1128/JB.05781-11

Goyal AK, Zylstra G (1996) Molecular cloning of novel genes for polycyclic aromatic hydrocarbon degradation from Comamonas testosteroni GZ39. Appl Environ Microbiol 62(1):230-236

Guo XJ, Lu ZY, Wang P, Li H, Huang ZZ, Lin KF, Liu YD (2015) Diversity and degradation mechanism of an anaerobic bacterial community treating phenolic wastewater with sulfate as an electron acceptor. Environ Sci Pollut Res 20:16121-16132. doi:10.1007/ s11356-015-4833-8

Hai R, Wang Y, Wang X, Li Y, Du Z (2014) Bacterial community dynamics and taxa-time relationships within two activated sludge bioreactors. PLoS One 9(3):e90175. doi:10.1371/journal.pone. 0090175

Hou W, Zhang L, Li Y, Zhang L, Li S, Ji L (2015) Distribution and health risk assessment of polycyclic hydrocarbons in soil from a typical contaminated urban coking sites in Shenyang city. Bull Environ Contam Toxicol 95:815-821. doi:10.1007/s00128-015-1677-3
Hughes JB, Hellmann JJ (2005) The application of rarefaction techniques to molecular inventories of microbial diversity. Methods Enzymol 397:292-308. doi:10.1016/s0076-6879(05)97017-1

Ibarbalz FM, Figuerola ELM, Erijman L (2013) Industrial activated sludge exhibit unique bacterial community composition at high taxonomic ranks. Water Res 47(11):3854-3386. doi:10.1016/j.watres. 2013.04 .010

Jin X, Li E, Lu S, Qiu Z, Sui Q (2013) Coking wastewater treatment for industrial reuse purpose: combining biological processes with ultrafiltration, nanofiltration and reverse osmosis. J Environ Sci 25: 1565-1574. doi:10.1016/S1001-0742(12)60212-5

Kampfer P, Lodders N, Warfolomeow I, Falsen E, Busse HJ (2009) Corynebacterium lubricantis sp. nov., isolated from a coolant lubricant. Int J Syst Evol Microbiol 59:1112-1115. doi:10.1099/ijs.0. 006379-0

Kertesz M, Kawasaki A (2010) Hydrocarbon degrading sphingomonads: Sphingomponas, Sphingobium, Novosphingobium and Sphingopysis. In: Timmis K (ed) Handbook of hydrocarbon and lipid microbiology. Springer, Berlin, pp. 1693-1705. doi:10.1007/ 978-3-540-77587-4 119

Kim YM, Park H, Cho K $\mathrm{H}$, Park JM (2013) Long term assessment of factors affecting nitrifying bacteria communities and $\mathrm{N}$-removal in a full-scale biological process treating high strength hazardous wastewater. Bioresour Technol 134:180-189. doi:10.1016/j.biortech. 2013.02.036

Kim YM, Park D, Lee DS, Park JM (2008) Inhibitory effects of toxic compounds on nitrification process for cokes wastewater treatment. J Hazard Mater 152(3):915-921. doi:10.1016/j.jhazmat.2007.07.065

Klankeo P, Nopcharoenkul W, Pinyakong O (2009) Two novel pyrenedegrading Diaphorobacter sp. and Pseudoxanthomonas sp. isolated from soil. J Biosci Bioeng 108(6):488-495. doi:10.1016/j.jbiosc. 2009.05.016

Kohda C, Ando T, Nakai Y (1997) Isolation and characterization of anaerobic indole- and skatole-degrading bacteria from composting animal wastes. J Gen Appl Microbiol 43(5):249-255

Lai P, Zhao H, Ye Z, Ni J (2008) Assessing the effectiveness of treating coking effluents using anaerobic and aerobic biofilms. Process Biochem 43(3):229-237. doi:10.1016/j.procbio.2007.11.012

Larsen SB, Karakashev D, Angelidaki I, Schmidt JE (2009) Ex-situ bioremediation of polycyclic aromatic hydrocarbon in sewage sludge. $\mathrm{J}$ Hazard Mater 164:1568-1572. doi:10.1016/j.jhazmat.2008.08.067

Letowski J, Juteau P, Villemur R, Duckett MF, Beaudet R, Lipine F, Bisaillon JG (2001) Separation of a phenol carboxylating organism from a two-member, strict anaerobic co-culture. Can J Microbiol 47(5):373-381. doi:10.1139/w01-023

Li YM, Gu GW, Zhao JF, Yu HQ, Qiu YL, Peng YZ (2003) Treatment of coke-plant wastewater by biofilm systems for removal of organic compounds and nitrogen. Chemosphere 52:997-1005. doi:10.1016/ s0045-6535(03)00287-x

Liu R, Yu Z, Guo H, Liu M, Zhang H, Yang M (2012) Pyrosequencing analysis of eukaryotic and bacterial communities in faucet biofilms. Sci Total Environ 435-436:124-131. doi:10.1016/j.scitotenv.2012.07.022

Ma Q, Qu Y, Shen W, Zhang Z, Wang J, Liu Z, Li D, Li H, Zhou J (2015a) Bacterial community compositions of coking wastewater treatment plants in steel industry revealed by Illumina high-throughput sequencing. Bioresour Technol 179:436-443. doi:10.1016/j.biortech. 2014.12.041

Ma Q, Qu Y, Zhang X, Liu Z, Li H, Zhang Z, Wang J, Shen W, Zhou J (2015b) Systematic investigation and microbial community profile of indole degradation processes in two aerobic activated sludge systems. Sci Rep 5:17674. doi:10.1038/srep17674

Ma J, Wang Z, Yang Y, Mei X, Wu Z (2013) Correlating microbial community structure and composition with aeration intensity in submerged membrane bioreactors by 454 high-throughput pyrosequencing. Water Res 47(2):859-869. doi:10.1016/j.watres. 2012.11.013 
Manefield M, Griffiths RI, Leigh MB, Ray F, Whiteley AS (2005) Functional and compositional comparison of two activated sludge communities remediating coking effluent. Environ Microbiol 7(5): 715-722. doi:10.1111/j.1462-2920.2004.00746.x

Maranon E, Vazquez I, Rodriguez J, Castrillon L, Fernandez Y (2008) Coke wastewater treatment by a three-step activated sludge system. Water Air Soil Pollut 192(1):155-164. doi:10.1007/s11270-0089642-y

McKew BA, Smith CJ (2010) Real-time PCR approached for analysis of hydrocarbon-degrading bacterial communities. In: Timmis KN (ed) Handbook of hydrocarbon and lipid microbiology. Springer-Verlag, Berlin, pp. 3995-4009. doi:10.1007/978-3-540-77587-4 311

Narayan KD, Pandey SK, Das SK (2010) Characterization of Comamonas thiooxidans sp. nov., and comparison of thiosulfate oxidation with Comamonas testosteroni and Comamonas composti. Curr Microbiol 61(4):248-253. doi:10.1007/s00284-010-9602-9

Parshina SN, Kleerebezem R, Sanz JL, Lettinga G, Nozhevnikova AN, Kostrikina NA, Lysenko AM, Stams AJM (2003) Soehngenia saccharolytica gen. nov., sp. nov. and Clostridium amygdalinum sp. nov., two novel anaerobic, benzaldehyde-converting bacteria. Int J Syst Evol Microbiol 53:1791-1799. doi:10.1099/ijs.0.02668-0

Pham VH, Park SJ, Roh Y, Roh DH, Rhee SK (2009) Diaphorobacter oryzae sp. nov., isolated from a thiosulfate-oxidizing enrichment culture. Int J Syst Evol Microbiol 59(2):218-221. doi:10.1099/ijs. $0.001669-0$

Schloss PD, Westcott SL, Ryabin T, Hall JR, Hartmann M, Hollister EB, Lesniewski RA, Oakley BB, Parks DH, Robinson CJ, Sahl JW, Stres B, Thallinger GG, Van Horn DJ, Weber CF (2009) Introducing mothur: open-source, platform-independent, community-supported software for describing and comparing microbial communities. Appl Environ Microbiol 75(23):7537-7541. doi:10.1128/AEM. 01541-09

Sharma NK, Philip L (2015) Treatment of phenolics, aromatic hydrocarbons, and cyanide-bearing wastewater in individual and combined anaerobic, aerobic, and anoxic bioreactors. Appl Biochem Biotechnol 175(1):300-322. doi:10.1007/12010-014-1262-y

Sharma NK, Philip L, Bhallamudi SM (2012) Aerobic degradation of phenolics and aromatic hydrocarbons in presence of cyanide. Bioresour Technol 121:263-273. doi:10.1016/j.biortech.2012.06. 039

Shoji T, Sueoka K, Satoh H, Mino T (2014) Identification of the microbial community responsible for thiocyanate and thiosulfate degradation in an activated sludge process. Process Biochem 49:1176-1181. doi: 10.1016/j.procbio.2014.03.026

Shu D, He Y, Yue H, Wang Q (2015) Microbial structures and community functions of anaerobic sludge in six full scale wastewater treatment plants as revealed by 454 high-throughput pyrosequencing. Bioresour Technol 186:163-172. doi:10.1016/j.biortech.2015.03. 072

Sogin ML, Morrison HG, Huber JA, Welch DM, Huse SM, Neal PR, Arrieta JM, Herndl GJ (2006) Microbial diversity in the deep sea and the underexplored "rare biosphere". P Natl Acad Sci USA 103(32):12115-12120. doi:10.1073/pnas.0605127103

Song G, Zhu C, Hu Y, Chen J, Cheng H (2013) Determination of organic pollutants in coking wastewater by dispersive liquid-liquid micro extraction/GC/MS. J Sep Sci 3(9-10):1644-1651. doi:10.1002/jssc. 201201151

Staib C, Lant P (2007) Thiocyanate degradation during activated sludge treatment of coke-ovens wastewater. Biochem Eng J 34(2): 122-130. doi:10.1016/j.bej.2006.11.029

Stolz A (2009) Molecular characteristics of xenobiotic-degrading sphingomonads. Appl Microbiol Biotechnol 81:793-811. doi:10. 1007/s00253-008-1752-3

Tago Y, Yokota A (2004) Comamonas badia sp. nov., a floc-forming bacterium isolated from activated sludge. J Gen Appl Microbiol $50: 243-248$
Vazquez I, Rodriguez J, Maranon E, Castrillon L, Fernandez Y (2006) Simultaneous removal of phenol, ammonium and thiocyanate from coke wastewater by aerobic biodegradation. J Hazard Mater 137(3): 1773-1780. doi:10.1016/j.jhazmat.2006.05.018

Wagner M, Loy A (2002) Bacterial community composition and function in sewage treatment systems. Curr Opin Biotechnol 13:218-227. doi:10.1016/S0958-1669(02)00315-4

Wang Q, Garrity GM, Tiedje JM, Cole JR (2007) Naive Bayesian classifier for rapid assignment of rRNA sequences into the new bacterial taxonomy. Appl Environ Microbiol 73(16):5261-5267. doi:10. 1128/AEM.00062-07

Wang W, Han H, Yuan M, Li H (2010) Enhanced anaerobic biodegradability of real coal gasification wastewater with methanol addition. $\mathrm{J}$ Environ Sci (China) 22(12):1868-1874. doi:10.1016/S10010742(09)60327-2

Wang X, Hu M, Xia Y, Wen X, Ding K (2012) Pyrosequencing analysis of bacterial diversity in 14 wastewater treatment systems in China. Appl Environ Microbiol 78(19):7042-7047. doi:10.1128/AEM. 01617-12

Wang X, Jin D, Zhou L, Wu L, An W, Zhao L (2014) Draft genome sequence of Advenella kashmirensis strain W13003, a polycyclic aromatic hydrocarbon-degrading bacterium. Genome Announc 2(1):e00003. doi:10.1128/genomeA.00003-14

Wang Z, Liu L, Guo F, Zhang T (2015b) Deciphering cyanide-degrading potential of bacterial community associated with the coking wastewater treatment plant with a novel draft genome. Microb Ecol 70(3): 701-709. doi:10.1007/s00248-015-0611-x

Wang W, Ma W, Han H, Li H, Yuan M (2011) Thermophilic anaerobic digestion of Lurgi coal gasification wastewater in a UASB reactor. Bioresour Technol 102:2441-2447. doi:10.1016/j.biortech.2010.10. 140

Wang C, Zhang M, Cheng F, Geng Q (2015a) Biodegradation characterization and immobilized strains' potential for quinoline degradation by Brevundimonas sp. K4 isolated from activated sludge of coking wastewater. Biosci Biotechnol Biochem 79:164-170. doi:10.1080/ 09168451.2014.952615

Wei X, Zhang Z, Fan Q, Yuan X, Guo D (2012) The effect of treatment stages on the coking wastewater hazardous compounds and their toxicity. J Hazard Mater 239-240:135-141. doi:10.1016/j.jhazmat. 2012.08.042

Wells GF, Park HD, Eggleston B, Francis CA, Criddle CS (2011) Finescale bacterial community dynamics and the taxa-time relationship within a full-scale activated sludge bioreactor. Water Res 45(17): 5476-5488. doi:10.1016/j.watres.2011.08.006

Yamada T, Imachi H, Ohashi A, Harada H, Hanada S, Kamamgata Y, Sekiguchi Y (2007) Bellilinea caldifistulae gen. nov., sp. nov. and Longilinea arvoryzae gen. nov., sp. nov., strictly anaerobic, filamentous bacteria of the phylum Chloroflexi isolated from methanogenic propionate degrading consortia. Int J Syst Evol Microbiol 57:2299 2306. doi:10.1099/ijs.0.65098-0

Yang Q, Angly FE, Wang Z, Zhang H (2011) Wastewater treatment systems harbor specific and diverse yeast communities. Biochem Eng J 58-59:168-176. doi:10.1016/j.bej.2011.09.012

Yuan X, Sun H, Guo D (2012) The removal of COD from coking wastewater using extraction replacement-biodegradation coupling. Desalination 289:45-50. doi:10.1016/j.desal.2012.01.002

Yuste L, Corbella ME, Turiegano MJ, Karlson U, Puyet A, Rojo F (2000) Characterization of bacterial strains able to grow on high molecular mass residues from crude oil processing. FEMS Microbiol Ecol 32(1):69-75. doi:10.1111/j.1574-6941.2000.tb00700.x

Zhang X, Qu Y, Ma Q, Zhang Z, Li D, Wang J, Shen W, Shen E, Zhou J (2015) Illumina MiSeq sequencing reveals diverse microbial communities of activated sludge systems stimulated by different aromatics for indigo biosynthesis from indole. PLoS One 10(4): e0125732. doi:10.1371/journal.pone.0125732 
Zhang T, Shao MF, Ye L (2012) 454 pyrosequencing reveals bacterial diversity of activated sludge from 14 sewage treatment plants. ISME J 6:1137-1147. doi:10.1038/ismej.2011.188

Zhang W, Wei C, Yan B, Feng C, Zhao G, Lin C, Yuan M, Wu C, Ren Y, $\mathrm{Hu} \mathrm{Y}$ (2013) Identification and removal of polycyclic aromatic hydrocarbons in wastewater treatment processes from coke production plants. Environ Sci Pollut Res 20:6418-6432. doi:10.1007/s11356013-1697-7

Zhao JL, Jiang YX, Yan B, Wei C (2014) Multispecies acute toxicity evaluation of wastewaters from different treatment stages in a coking wastewater-treatment plant. Environ Toxicol 33(9):19671975. doi:10.1002/etc. 2638

Zhu X, Tian J, Liu C, Chen L (2013) Composition and dynamics of microbial community in a zeolite biofilter-membrane bioreactor treating coking wastewater. Appl Microbiol Biotechnol 97:87678775. doi:10.1007/s00253-012-4558-2

Zhu S, Wu H, Wei C, Zhou L, Xie J (2016) Contrasting microbial community composition and function perspective in sections of a fullscale coking wastewater treatment system. Appl Microbiol Biotechnol 100:949-960. doi:10.1007/s00253-015-7009-Z 